\title{
Translational models for vascular cognitive impairment: a review including larger species
}

\author{
Atticus H. Hainsworth ${ }^{1,2^{*}}$, Stuart M. Allan ${ }^{3}$, Johannes Boltze ${ }^{4,5}$, Catriona Cunningham ${ }^{3}$, Chad Farris ${ }^{6,7}$, \\ Elizabeth Head ${ }^{8}$, Masafumi Ihara ${ }^{9}$, Jeremy D. Isaacs ${ }^{1,2}$, Raj N. Kalaria ${ }^{10}$, Saskia A. M. J. Lesnik Oberstein ${ }^{11}$, \\ Mark B. Moss ${ }^{6,7}$, Björn Nitzsche ${ }^{12,13,14}$, Gary A. Rosenberg ${ }^{15}$, Julie W. Rutten ${ }^{11,18}$, Melita Salkovic-Petrisic ${ }^{16}$ \\ and Aron M. Troen ${ }^{17}$
}

\begin{abstract}
Background: Disease models are useful for prospective studies of pathology, identification of molecular and cellular mechanisms, pre-clinical testing of interventions, and validation of clinical biomarkers. Here, we review animal models relevant to vascular cognitive impairment ( $\mathrm{VCI}$ ). A synopsis of each model was initially presented by expert practitioners. Synopses were refined by the authors, and subsequently by the scientific committee of a recent conference (International Conference on Vascular Dementia 2015). Only peer-reviewed sources were cited.

Methods: We included models that mimic VCl-related brain lesions (white matter hypoperfusion injury, focal ischaemia, cerebral amyloid angiopathy) or reproduce VCl risk factors (old age, hypertension, hyperhomocysteinemia, high-salt/high-fat diet) or reproduce genetic causes of VCI (CADASIL-causing Notch3 mutations).

Conclusions: We concluded that (1) translational models may reflect a VCl-relevant pathological process, while not fully replicating a human disease spectrum; (2) rodent models of $\mathrm{VCl}$ are limited by paucity of white matter; and (3) further translational models, and improved cognitive testing instruments, are required.
\end{abstract}

Keywords: Vascular dementia, Vascular cognitive impairment, VCID, Experimental models, In vivo models, Translational models

\section{Introduction}

Vascular cognitive impairment (VCI) is a spectrum of clinical disease states [1-4] that range from poststroke mild cognitive impairment or dementia following a large artery stroke, through 'sporadic' small vessel disease (SVD), to pure genetic small vessel arteriopathy (CADASIL, CARASIL, COL4A1/4A2 mutations) $[1,5,6]$. The most common pathology underlying $\mathrm{VCI}$ is cerebral SVD, which leads to focal lacunar ischaemic infarcts, diffuse white matter lesions, and small haemorrhages in deep brain areas [3, 4]. These disease states manifest in a

\footnotetext{
* Correspondence: ahainsworth@sgul.ac.uk

${ }^{1}$ Clinical Neurosciences (J-OB) Molecular and Clinical Sciences Research Institute, St George's University of London, Cranmer Terrace, London SW17 ORE, UK

${ }^{2}$ Department of Neurology, St George's University Hospitals NHS Foundation Trust, London, UK

Full list of author information is available at the end of the article
}

spectrum of cognitive impairments. Further complexity arises as most clinical dementia in older persons is likely to be 'mixed' as a result of Alzheimer's disease (AD) combined with vascular pathology $[7,8]$. While characterisation of the neuropathological and radiological features of human VCI has improved over the last two decades (see adjoining articles) the molecular changes that underpin these characteristics remain elusive [6]. VCI currently lacks symptomatic treatment (comparable to donepezil for $\mathrm{AD}$ ) and molecular targets (comparable to tau, amyloid precursor protein (APP) and $\beta$-amyloid (A $\beta)$ ).

Because VCI arises from a spectrum of diseases, no single model will reproduce all pathological and cognitive features of SVD or VCI [6, 9-12] (Table 1). Furthermore, as with any animal model for dementia, the behavioural-cognitive phenotype of any given model can never fully represent human cognitive deficits. We define a 'translational' model as 


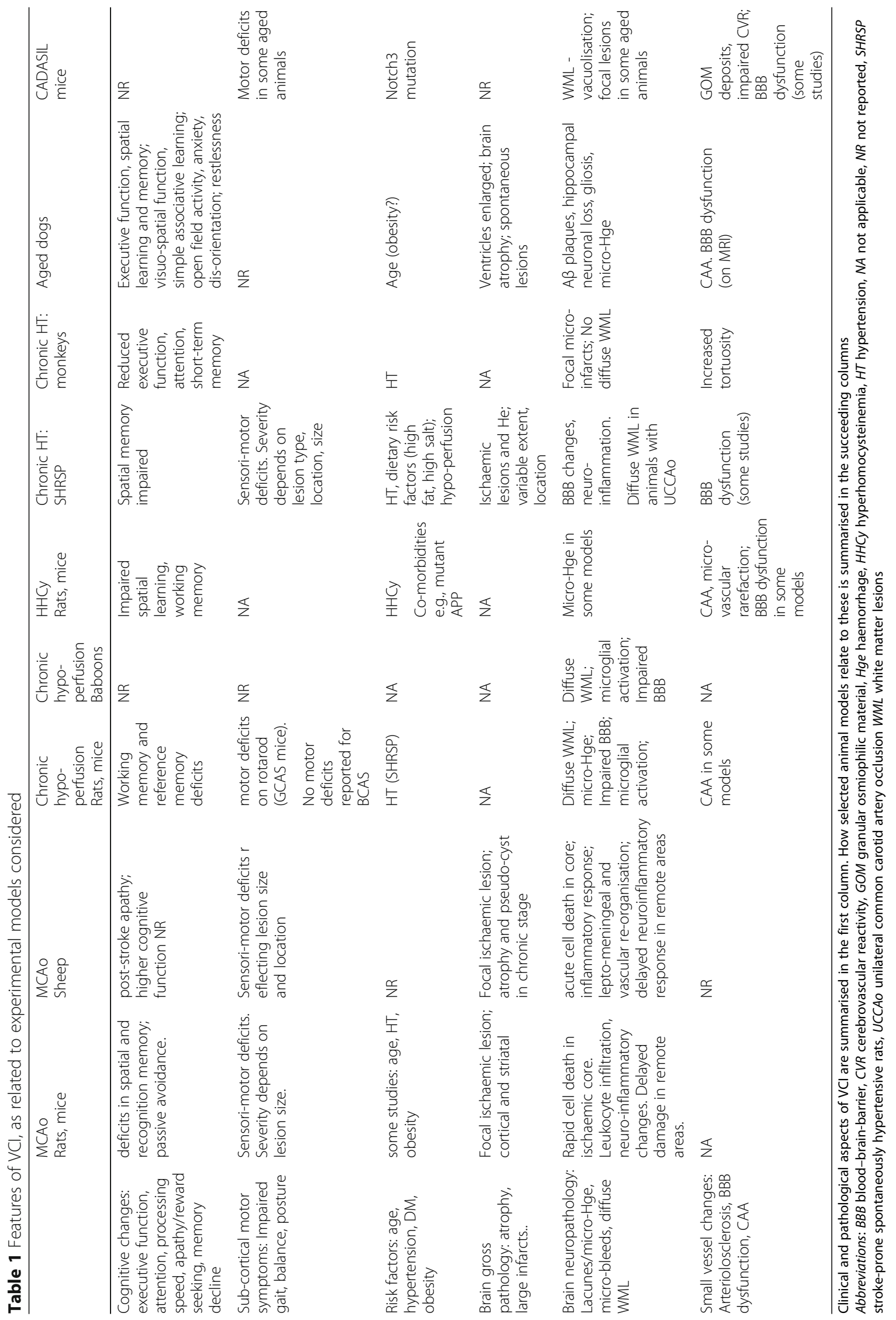


one that impacts on clinical practice [13]. Therefore, in order to be translational an animal model should reproduce at least one of the pathological processes in human VCI $[6,12,14]$. A fully translational model would permit (1) prospective studies of the timescale and the sequence of events during development of the pathological process, (2) identification of novel molecular, cellular and physiological mechanisms, (3) pre-clinical testing of drugs and other interventions, for proof-of-concept studies, (4) preclinical testing of safety profile of drugs, optimal dosing and time-scale, and (5) validation of clinical biomarkers and endpoints such as radiological or biochemical signatures. Models representing the initiating factors would allow translation of preventive strategies, whereas models of advanced disease states allow testing of therapeutic interventions. It is appropriate and timely to seek international accord on such models [15]. Following the recent NIH-sponsored Alzheimer's Disease-Related Dementias 2016 Summit (https://aspe.hhs.gov/alzheimers-disease-related-dementias-adrd-summit-2016-prioritized-research-mi lestones), the number one recommendation for VCI was to "Establish new animal models that: (i) reproduce small vessel disease and other key pathogenic processes thought to result in cognitive impairment; (ii) are easily applicable to both VCID and AD research for advances in mixed etiology dementias; (iii) address vascular contributions to dementia via both white matter and grey matter or (iv) include genetic and acquired conditions that are associated with VCID".

Here, we review published models relevant to VCI, including rodents and emphasising larger species. This review is the result of discussions between experts from 12 laboratories across seven countries. Relevant systematic reviews are available $[10,12]$.

\section{Overview of experimental species Rodents}

We have included models of focal ischaemia (middle cerebral artery occlusion; MCAo) [16-19] as this is a validated, translational model of cerebrovascular injury. Global hypoperfusion models include bilateral carotid artery occlusion (BCAo) in rats [20] and bilateral carotid artery stenosis (BCAS) using wire coils in mice [21, 22]. A refinement of the BCAo protocol employs constrictor cuffs to give a gradual arterial occlusion over approximately 1-2 days [20]. These global models produce ischaemic white matter lesions, likely reflecting the low baseline perfusion of white matter. Other pathologies can also occur, including hippocampal cell death, small haemorrhages and vascular amyloid deposition. Genetic alterations include inbred strains (e.g., SHR, stroke-prone spontaneously hypertensive rats (SHRSP)) [23-26] or transgenic manipulations (e.g., Notch3 mutant strains) [27-29]. VCI-relevant animals can also result from manipulation of risk factors, such as age, hypertension, diabetes mellitus, hyperhomocysteinemia or a high-salt/ high-fat ('fast food') diet [14, 25, 26, 30, 31].

\section{Larger species}

Larger animals have a longer natural life span than rodents. Experimental ruminants (sheep, goats) are predominantly used to simulate acute cerebrovascular pathologies such as ischaemic stroke [32-34] and cerebral haemorrhage [35]. In domestic dogs, hypercaloric or unbalanced diet, lack of physical exercise and dyslipidemia are prevalent [36]. As in humans, hypertension [37] and cerebral arteriosclerosis [38] are often observed in older subjects. Consequently, a canine cognitive dysfunction syndrome, featuring some clinical aspects of VCI, has been described, particularly in breeds living long enough ( $>9$ years) to fully develop a neurological phenotype [39-42]. In cats, less is known about the relation between aging, vascular pathologies and cognitive decline. $A \beta$ and tau pathologies have been described in cats showing clinical signs of cognitive decline [43-45]. Hypertension associated with arteriosclerosis, as well as small, multifocal cerebral haemorrhages, have also been reported for felines [46].

Behavioural paradigms for cognitive assessment in larger species have been reported from specialist centres for sheep, pigs and cattle [41, 47-51]. The most advanced cognitive abilities are seen in primates, for which sophisticated cognitive tools have been developed [52, 53]. Hypercaloric diet can decelerate aging and prevent microvascular pathologies and cognitive decline in primates [54, 55], without changing the lifespan [56]. Nevertheless, physiological aging can take decades in primates, and studies relevant to VCI may be restricted to specialised colonies $[57,58]$.

Large animal models allow clinical neuroimaging without significant limitations in resolution, acquisition time or data analysis. MRI protocols are now available for dogs [59], cats [60], non-human primates [61-63], pigs $[64,65]$ and sheep [66]. MRI (T1, T2, FLAIR) is advantageous for analysis of tissue volume and lesions [66], as well as for anatomical evaluation of particular brain areas [67]. Perfusion and diffusion-weighted sequences reveal cerebral blood flow (CBF) dynamics and vascular permeability [68]. Templates, automatic segmentation and labelling routines for larger species are essential for studies aiming at quantitative morphometric analysis of MRI and/or PET images. Automatic labelling and processing routines have been developed for rhesus and cynomolgus monkeys [61, 69, 70], sheep [67], pigs [71, 72], and dogs [73]; this enables efficient, observer-independent analysis of grey and white matter regions.

\section{Review methods}

For each model, expert practitioners used web-based searches and their own expertise to write a section of 
the review. All synopses were circulated for editing by all authors, and subsequently by the scientific committee of an international conference (International Conference on Vascular Dementia, ICVD2015, Ljubjiana, Slovenia). Only peer-reviewed sources in English were included.

\section{Ethical statements on animal data}

Sheep experiments from which data were derived were approved by the responsible authorities for University of Lübeck and University of Leipzig, Germany (animal protocol numbers TVV33/09, TVV09/11, TVV33/12). Experiments using monkeys were approved by the Institutional Animal Care and Use Committee of Boston University Medical Center. All procedures with dogs were conducted in accordance with University of Kentucky approved animal protocols (2009-0483) and the NIH Policy on Humane Care and Use of Laboratory Animals.

\section{Expert reviews of specific models}

Large Vessel Ischaemia - Middle Cerebral Artery Occlusion (MCAo) in Rodents

MCAo induces acute focal ischaemia bordered by a partially ischaemic penumbra [74, 75]. While recovery of sensorimotor function is well-characterised using behavioural tests, there is less literature on cognitive impairment [76]. Spatial learning, assessed by Y- and T-maze tests, is hippocampus-dependent, but as other regions are also required, including prefrontal cortex and basal forebrain, these tests are relevant to the MCAo model [77]. Following MCAo, male rats showed decreased rates of spontaneous alternation compared with sham-operated animals at day 21 post-stroke [78]. At 4 days post-MCAo, male mice spend less time exploring a novel object than sham animals [79]. Fear-motivated tasks such as passive avoidance have also been used to assess cognitive impairment after stroke [80]. While passive avoidance is a simple task, it is stressful so could confound results of other behavioural tests [76].

\section{Larger species: sheep with vascular ischaemic lesions}

Permanent [32] and transient [34] MCAo have been performed in sheep, resulting in well controlled and reproducible lesion sizes (Fig. 1). Histopathological investigations revealed both grey and white matter changes, including glial scar formation, microglial activation and replacement of the tissue by new formation of blood vessels and foamy fat cells [33]. Moreover, ovine models have been successfully employed to test experimental therapeutic paradigms in short- [81] and longer-term (up to 7 weeks) approaches [33], during which benefits of single- and multi-mode imaging protocols became evident.

A caveat in this species (and other domestic mammals) is the rete mirabile epidurale rostrale, a local arborisation within the carotid artery [82]. This often necessitates a

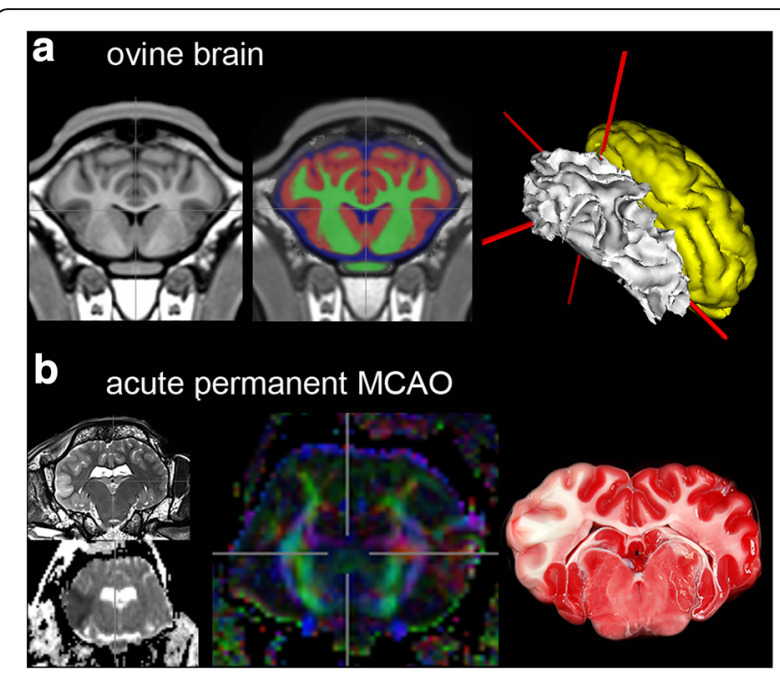

Fig. 1 Focal ischaemic lesions in ovine brain. a Adult sheep brain in coronal section. $\mathrm{T} 1$-weighted population-averaged brain template (left), depiction of grey and white matter, as well as cerebrospinal fluid (middle panel, overlay on template) and surface reconstruction of white (white) and grey matter (yellow) in stereotactic space (right). Grey and white matter spaces are derived from a priori tissue probability maps. b Focal ischaemic lesion, $6 \mathrm{~h}$ after permanent middle cerebral artery occlusion (MCAO). Hyperintense area is seen in the left temporal cortex and medulla in T2-weighted TSE MRI (left-top). In this area, a decreased diffusion in apparent diffusion coefficient maps of diffusion weighted imaging (DWI-ADC, left-bottom) is visible. Fractional anisotropy map of diffusion tensor imaging (DTI-FA, middle panel) reveals a loss of fibre integrity. Following sacrifice and brain removal, the mitochondrial marker TTC labels living cells (red). The ischaemic lesion is unlabelled by TTC (right)

transcranial approach for MCAo. Leaving the trepanation covered only by soft tissue reduces intracranial pressure, which greatly increases long-term survival. In mild and severe global cerebral ischaemia models in sheep, it became evident that the basilar artery can contribute a higher proportion of CBF than in humans [83]. After prior bilateral clamping of both common carotid arteries for 4-30 min, no lesions were found in brains of sheep subjected to the method for less than 10 min. Longer duration produced neuronal changes of several brain regions, similar to those described in other species.

\section{Primates and rodents: chronic brain hypoperfusion}

With the assumption that reducing CBF is a common feature of VCI $[3,84,85]$, the original mouse BCAS model was developed by placing microcoils on the carotid arteries to induce cerebral hypoperfusion [86]. While complete ligation of the carotid arteries (i.e., BCAo) substantially increased mortality, mice can withstand up to $50 \%$ BCAS [22, 87]. Monitoring cognitive function using the $\mathrm{Y}$, radial arm, Barnes maze and Morris water maze has provided robust evidence that the BCAS model replicates some features of $\mathrm{VCI}$, in 
particular the deficit of working memory [10, 86, 87]. In BCAS, global CBF drops rather abruptly. With the same principle as BCAS, ameroid micro-constrictors made of casein (which swells on absorbing water) were placed around the carotid arteries to provide a more gradual stenosis [20]. Ameroid constrictors have also been applied to spontaneously hypertensive rats [20]. Further refinements have allowed the development of mice models that exhibit subcortical infarcts and white matter damage by surgical implantation of an ameroid constrictor to the right common carotid artery and placement of a microcoil to the left common carotid artery to induce approximately $50 \%$ arterial stenosis; this is referred to as gradual carotid artery stenosis [88]. There was gradual reduction of $\mathrm{CBF}$ over 28 days, and multiple infarct damage in right subcortical regions, including the corpus callosum, internal capsule, hippocampal fimbria, and caudoputamen in $81 \%$ of mice $[88,89]$. These hypoperfusion models are discussed further elsewhere [12].

A baboon (Papio anubis) model evaluated whether partial cerebral ischaemia or oligaemia resulting from reduced blood flow to the brain induces white matter pathology consistent with SVD or AD-like changes. The baboon model is ideal to relate to AD because it exhibits both $\mathrm{a} \beta$ and tau pathology with ageing and carries APOE4 associated with AD pathology. Adult, male baboons were subjected to three-vessel occlusion by complete ligation of the internal carotid arteries bilaterally, and occlusion of the left vertebral artery. We have recently reported subcortical and white matter changes in animals to 28 days after three-vessel occlusion [90]. This model is useful to evaluate interventions at various stages and specifically examine the effects of ageing, high-fat diet, hypertension and neuroinflammation. Ameroid constrictors to replicate a gradual reduction in CBF may be a future refinement $[84,85]$.

\section{SHRSP with modified diet or hypoperfusion}

Hypertensive rat strains can undergo white matter changes [23-26, 91]. SHRSP typically live for 9-12 months before developing ischaemic and haemorrhagic stroke lesions [12, 92]. When a low-protein, high-salt diet is given to the SHRSP, lesions and death are accelerated [93]. Starting the diet after 6 weeks of life leads to haemorrhagic strokes, but delaying the onset of the diet until the 12th month slows the onset of strokes and allows the damage to the white matter to occur earlier [25]. The white matter damage results from hypoxic hypoperfusion [94]. In a recent study, minocycline, a tetracycline derivative with the ability to inhibit matrix metalloproteinases, reduced white matter damage and reversed the behavioural changes in SHRSP [26]. For a more extensive discussion of SHRSP, see [12, 92].

\section{Dietary induction of hyperhomocysteinemia}

Elevated circulating homocysteine (hyperhomocysteinemia) is caused by a variety of genetic, physiologic and dietary conditions extensively studied in rodents [95-98]. These cause cognitive impairment in $A p o E$ null mice, transgenic mouse models of Alzheimer's disease, and wildtype mice and rats [31, 99, 100], with surprisingly little neurodegeneration or inflammation. Feeding wildtype C57BL6J mice a diet deficient in three B-vitamins (folate, B12 and B6) for 10 weeks resulted in hyperhomocysteinemia, microvascular rarefaction and impaired performance in the Morris water maze [31, 100]. The same dietary regime in APP transgenic mice worsened cognitive impairment [101], and in combination with excess methionine in dual mutant APP/PS1 mice, the diet induced the redistribution of amyloid from brain parenchyma to the microvasculature along with microhaemorrhages, as determined by histology and MRI $[30,102]$. In Sprague-Dawley rats, folate-deficiency alone was sufficient to induce homocysteinemia and cognitive impairment, and to reduce cerebral blood volume and reactivity measured by absolute, non-invasive, near-infrared spectroscopy [103-105]. For further discussion of hyperhomocysteinemia models, see [12].

Dietary modification can be applied to most species, models and co-morbidities. Caveats are that dietary models typically have higher variability and more subtle effects than genetic or pharmacological models. Outcomes are sensitive to dietary formulation and feeding. This underscores the need for biochemical and metabolic verification of the diet in brain and the periphery. While chronic folate and B12 deficiency in humans causes macrocytic anaemia and myeloneuropathy, these outcomes are almost never observed in rodent models. Associations between microvascular rarefaction and cognitive impairment, in the absence of neurodegenerative changes have been observed in other models, including mice fed a high-fat diet [106], aged rats [107], and irradiated rats [108].

\section{Primates with chronic hypertension}

The basis of this model is the induction of hypertension by surgical coarctation of thoracic aorta in the rhesus monkey [52, 109-111]. A segment of the thoracic aorta is mobilised and dissected without injuring the mediastinal and intercostal branches. The external diameter of the same segment is measured and then narrowed to a luminal diameter of $2.0-2.5 \mathrm{~mm}$ (Fig. 2). A pressure transducer inserted into the femoral artery is advanced through the surgical site. Typically, systolic/diastolic pressure is $170 / 100 \mathrm{mmHg}$ above the coarctation and 80/50 mmHg (normal for rhesus monkeys) below.

Given the known effects of chronic hypertension on attention, memory and executive function in humans, 
a

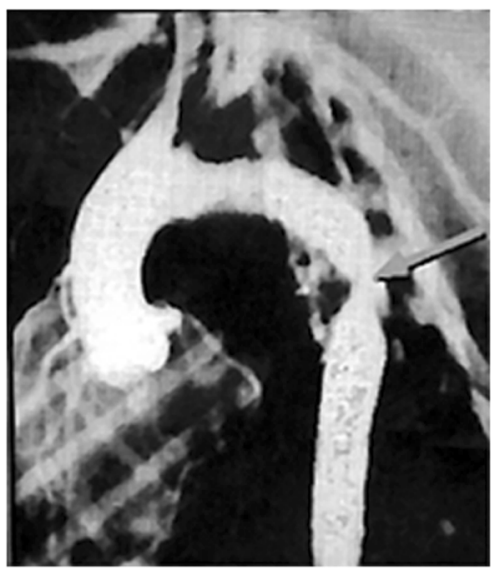

C

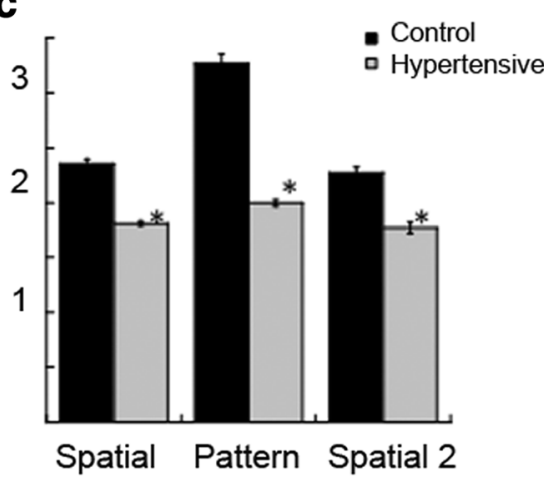

b

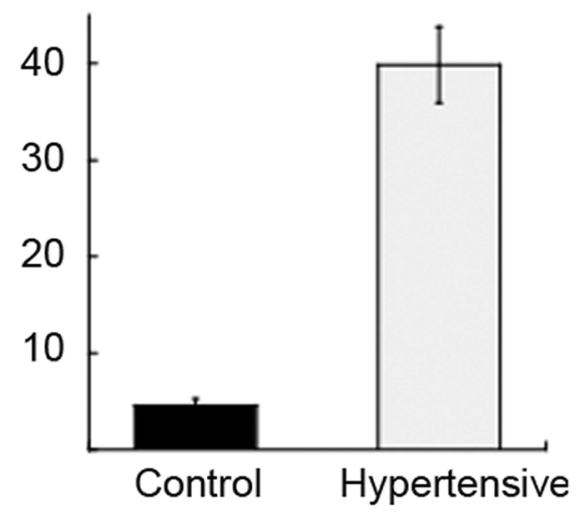

d

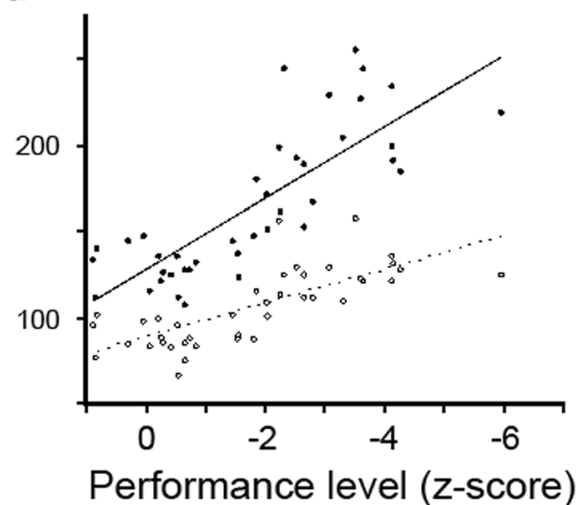

Fig. $2 \mathrm{VCl}$ in adult monkeys with surgically-induced chronic hypertension. a Arteriogram showing surgical coarctation of the thoracic aorta (arrow) in the monkey. $\mathbf{b}$ Delayed non-matching to sample (DNMS) scores for re-acquisition of the basic task. Y-axis: errors to criterion for control (sham-operated, black bar) and hypertensive monkeys (grey bar). c Delayed recognition span (DRS) test scores. Y-axis: group mean span, for control (black bars) and hypertensive monkeys (grey bars). $\mathbf{d}$ Blood pressure correlates with overall cognitive function. Y-axis: blood pressure (mmHg). $X$-axis: cognitive function index. The level of impairment on this index was significantly and linearly related to both systolic (black symbols, solid line; $r=0.80, P<0.005$ ) and diastolic blood pressure (open symbols, dashed line; $r=0.75, P<0.005$ ). Modified from [52] with permission

these domains were assessed in adult primates (5-11 years of age). The tasks consisted of an automated task of simple attention, two tasks of memory function, the delayed non-matching to sample task (DNMS) [112, 113] and the delayed recognition span task [114, 115], and a primate analogue to the Wisconsin Card Sort task, the Conceptual Set-Shifting Task (CSST) [116]. Performance was compared with sham-operated controls that underwent every stage of the surgical procedures up to, but not including, narrowing of the aorta. Animals with coarctation were grouped into borderline $(135-150 \mathrm{mmHg})$ or hypertensive (> $150 \mathrm{mmHg}$ ).

On the task of simple attention in which monkeys are required to select the same target stimulus on the touchscreen, there was a positive correlation between response time and systolic and mean blood pressure; hypertensive (but not borderline) animals were significantly impaired relative to the sham-operated group. Hypertensive monkeys were impaired on a task that required orienting to, and then responding by touching, a randomly-presented visual stimulus. Unlike normotensive animals, hypertensive monkeys did not benefit from the presentation of a cue that preceded the target stimulus. The effect did not appear to be related to motivational state as there was no difference in the number of missed trials. These findings suggest a reduction in the speed of processing in the stimulus-response chain.

The findings on memory assessment revealed a significant difference among the groups on the DNMS up to 12 months post-surgery. Hypertensive monkeys re-learned the DNMS task less efficiently than sham-operated controls (Fig. 2). On both the spatial and pattern conditions of the delayed recognition span task, the performance of the hypertensive monkeys was significantly impaired with 
respect to the control monkeys, suggesting that, in addition to affecting attentional function, hypertension produced an impairment in 'rule learning'.

The CSST requires the monkey to establish a cognitive set based on a reward contingency, to maintain that set for a period of time, and then shift the set as the reward contingency changes. A subset of hypertensive monkeys was unimpaired on the initial phase of the CSST (a simple three choice discrimination). In contrast, hypertensive monkeys were impaired at abstracting the initial concept of colour on the CSST and were subsequently impaired when shifted to the concept of shape, when shifted back to the concept of colour, and again when shifted back to the concept of shape. The findings from this task suggest that the two groups of monkeys were able to learn a stimulus reinforcement contingency at the same rate and that the impairment seen on the CSST is most likely one of abstraction and cognitive flexibility.

Overall, hypertension significantly influenced higher cognitive function. Blood pressure correlated with a composite z-score (similar to an IQ score), suggesting a direct relationship between blood pressure and cognition (Fig. 2).

Various neuropathologies are seen in this primate model, including tortuous small vessels, hemosiderinfilled macrophages and, most conspicuously, microinfarcts in both grey and white matter [110, 111]. The micro-infarcts are of irregular shape and relatively uniform size (average maximum diameter $\sim 0.5 \mathrm{~mm}$ ). In the grey matter, these lesions were characterised by a total loss of neurons, and in white matter by marked loss of myelinated fibres.

\section{Larger species: aged canine model}

Aging dogs spontaneously develop cerebrovascular pathology linked to cognitive decline [41, 42], including cortical atrophy and ventricular enlargement (Fig. 3). Cognitive impairment was evident on measures reflecting learning and memory, and a subset of aged animals became severely impaired [41, 42]. A strength of the model is that $A \beta$, critically involved with plaque accumulation and cerebral amyloid angiopathy (CAA), is very similar in dogs and humans [117-119]. Vascular and perivascular abnormalities and cerebrovascular $A \beta$ pathology are frequently found in aged dogs [40, 120-124]. Dogs may be a suitable model system in which to examine the consequences of CAA on cognition [125]. As in humans, canine CAA is associated with cerebral haemorrhage $[40,121]$, the occipital cortex being particularly vulnerable [126]. Several environmental manipulations and pharmacological studies that modify lifestyle factors have been successfully implemented in canine models, with some showing significant benefits to cognition [41]. Canines have also been used as a model for ischaemic stroke. Both FLAIR and T2* (sensitive to hemosiderin)

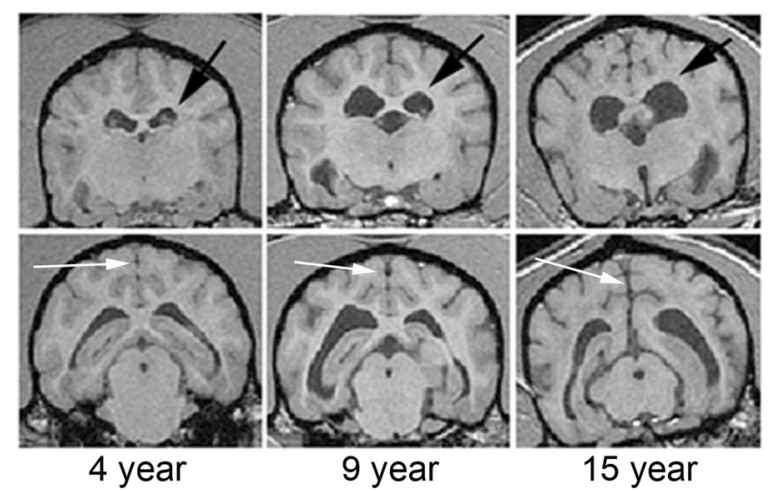

Fig. 3 Structural MRI of canine brains. Coronal MRI scans (1.5 Tesla) of 4-, 9-, and 15-year-old dogs, taken from locations at the level of thalamus (upper row) and hippocampus (lower row). Older animals show marked increase in ventricular volume (black arrows) and cortical atrophy, with deep gyri and widened sulci (white arrows).

Three-dimensional images across the whole brain were acquired using a spoiled gradient recall (SPGR) sequence to obtain detailed anatomic images. Modified from [129] with permission

imaging show significant white matter hyperintensities [127]. Loss of white matter integrity may be a consequence of CAA; for example, dogs aged from 1 to 20 years exhibited a progressive loss of myelin basic protein, correlated with age and with increasing CAA [128].

The canine brain displays substantial age-associated morphological changes [129-131]. Gadolinium-enhanced MRI revealed reduced blood-brain barrier function with age, as well as reduced cerebrovascular volume [129]. Characterising cognitive function in aging dogs requires many months, and treatment studies may take several years. In comparison to rodent models, they require significant veterinary care as they become older. Radiological outcome measures that reflect in vivo CAA (e.g., SWI scans) have not yet been published.

\section{Mouse models for monogenic small vessel disease (CADASIL)}

CADASIL (Cerebral Autosomal Dominant Arteriopathy with Subcortical Infarcts and Leukoencephalopathy) is a monogenic archetype for SVD, caused by cysteine-altering missense mutations in NOTCH3. CADASIL patients develop progressive white matter lesions from early adulthood, followed by cognitive decline and recurrent subcortical infarctions [132]. Conventional transgenic murine models expressing mutant human NOTCH3 from a cDNA construct [133-135] recapitulate some aspects of the CADASIL vascular phenotype (vascular Notch3 accumulation and granular osmiophilic material on electron microscopy) $[12,92]$. In only one transgenic model, with 4-fold overexpression of mutant Notch3, the mice developed disturbed cerebrovascular reactivity (from 5 months of age), reduced CBF (from 12 months) and white matter 
damage (from 18 months) [27]. A novel transgenic mouse strain containing genomic human $\mathrm{NOTCH} 3$ has recently been developed [136]; these animals show early-onset vascular Notch3 accumulation (from 6 weeks). A knock-in model, made by introducing a mutation in endogenous Notch3, developed a CADASIL clinical phenotype (at 20 months) [137]. Stroke lesions, microbleeds and motor deficits were seen only in a minority of mutant mice (5-12\%). Despite the fact that cognition has not yet been characterised in these murine models, they offer a valid pathogenetic representation of human CADASIL and may be an important pre-clinical model in which to test VCI therapies for efficacy.

\section{Discussion and conclusions}

As noted previously [9-11, 14], no experimental model replicates all pathologic and cognitive aspects of human VCI (Table 1). Animal models are useful to reflect a pathological process (e.g., white matter hypoxia, arterial fibrosis, amyloid accumulation) rather than a human disease. Old dogs with canine cognitive dysfunction syndrome and aged primates ( $>20$ years of age) being possible exceptions, none of the models discussed here results in a 'demented' animal. That said, all the animal models considered above reproduce at least one of the pathological processes in human VCI. Because the sequence of events leading from experimental challenge to brain pathology, and thus to VCI, can be characterised in animal models (and interventions imposed), the models may help to identify pathways that lead to VCI. As the pathogenesis of SVD, the most common cause of VCI, remains unknown, a valid model of SVD-dependent VCI remains a challenge. Making these conceptual and biological limitations explicit will expedite the development and appropriate use of translational models for VCI.

There are several general limitations in the extant literature. Most animal studies involve short-term followup (typically, less than 4 weeks). Male animals are generally used and females usually avoided due to influences of the reproductive cycle. Few studies have correlated cognitive changes with anatomical changes, as seen by pathology or MRI. Most of the available cognitive paradigms are derived from AD models. Many experimental studies are under-powered (i.e., use a small number of animals) and few are replicated.

We have a number of recommendations for the VCI research community. First, it would be advantageous to increase our knowledge and experience in larger species with more abundant white matter and gyrencephalic brain anatomy. This is especially important given the central role of white matter lesions in human VCI. Second, robust neuropsychological methods for assessing VCI in experimental animals (particularly larger species) would be beneficial. Cognitive impairment (and recovery) are the most complex aspects of human VCI, and will likely differ between animals and humans (for example, experimental species lack spoken language). Thus, aspiring to a precise behavioural replication in an animal may not be possible. Nevertheless, a core toolkit of validated, reproducible, species-appropriate tests of a cognitive phenotype is required. With respect to SVD, simple behavioural indicators analogous to the key cognitive features of the syndrome in humans (impaired processing speed, apathy and executive dysfunction) should be welcome. Third, progress on translational VCI models will be more rapid if high standards of 'Methodological quality' [15] outlined in ARRIVE guidelines [138] and in previous translational consensus documents $[139,140]$ are followed. Specifically, random allocation of animals to experimental groups and blinded assessment of outcomes was quite rare in earlier studies (prior to 2010) [10]. Future experimental studies should adhere to available guidelines on experimental design, regarding a priori statistical power calculation, randomisation, blinding of observers, and confirmation by at least two independent laboratories [15, 138-140]. It appears likely that negative outcomes of animal studies are rarely published. Fourth, as neuroimaging (particularly MRI) has a central role in human VCI, future pre-clinical studies will be enhanced by brain imaging data. Radiological features (diffuse white matter lesions, lacunar infarcts) are the main clinical biomarkers of SVD. Hence, correlative studies relating MRI to brain pathology in animals will continue to be informative.

Experiments using gyrencephalic species may be costly and long in duration to afford sufficient statistical power. A possible solution is a step-wise approach that employs rodents to study fundamental aspects of cerebrovascular disease common to all species, and large animals to study aspects of VCI that require a large gyrencephalic brain. Extending studies across species will clarify molecular, cellular and physiological events that lead from vascular disease to neuronal injury and cognitive dysfunction in humans, and improve the likelihood of achieving new preventive and therapeutic interventions in VCI.

\section{Abbreviations \\ BCAo: Bilateral carotid artery occlusion; BCAS: Bilateral carotid artery stenosis; CAA: Cerebral amyloid angiopathy; CBF: Cerebral blood flow; \\ CSST: Conceptual set-shifting task; DNMS: Delayed non-matching to sample task; MCAo: Middle cerebral artery occlusion; SHRSP: Stroke-prone spontaneously hypertensive rats; SVD: Small vessel disease; VCl: Vascular cognitive impairment}

\section{Acknowledgements}

We are grateful to Professor Amos D Korczyn for his contributions to the VCl field and for his helpful comments on this review.

\section{Funding}

AHH gratefully acknowledges funding from Alzheimer's Drug Discovery Foundation (ADDF grant no. 20140901), Alzheimer's Society UK (PG146/151) and Alzheimer's Research UK (PPG2014A-8). SMA received research funding 
from the British Heart Foundation and EPSRC (UK). CC is funded by the MRC (UK) Centre for Doctoral Training in Regenerative Medicine (grant no. EP/L014904/1). AMT was supported in this work by Israel Science Foundation (ISF) Grant 1353/11.

\section{Availability of data and material}

Data sharing not applicable to this article as no datasets were generated or analysed during the current study.

\section{Authors' contributions}

$\mathrm{AHH}$ participated in study conception and design, and in drafting of the manuscript and its critical revision for important intellectual content. SMA, CC, CF, EH, MI, RNK, SAJLO, MBM, GAR, and JWR participated in acquisition of data and critical revision of the manuscript for important intellectual content. $\mathrm{JB}, \mathrm{BN}$ and AMT participated in conception and design, acquisition of data, and critical revision of the manuscript for important intellectual content. JDI and MSP participated in conception and design and critical revision of the manuscript for important intellectual content. All authors read and approved the final manuscript.

\section{Competing interests}

The authors declare that they have no competing interests.

\section{Consent for publication}

Not applicable.

\section{Ethics approval and consent to participate}

Human data or human tissue: Not applicable. Animal experiments: see Methods section.

\section{Author details}

'Clinical Neurosciences (J-OB) Molecular and Clinical Sciences Research Institute, St George's University of London, Cranmer Terrace, London SW17 ORE, UK. ${ }^{2}$ Department of Neurology, St George's University Hospitals NHS Foundation Trust, London, UK. ${ }^{3}$ Faculty of Biology, Medicine and Health, University of Manchester, Manchester M13 9PT, UK. ${ }^{4}$ Department of Translational Medicine and Cell Technology, University of Lübeck, Lübeck, Germany. ${ }^{5}$ Neurovascular Research Laboratory, Massachusetts General Hospital and Harvard Medical School, Charlestown, MA, USA. ${ }^{6}$ Department of Anatomy \& Neurobiology, Boston University School of Medicine, Boston, MA, USA. ${ }^{7}$ Department of Neurology, Boston University School of Medicine, Boston, MA, USA. ${ }^{8}$ Department of Pharmacology \& Nutritional Sciences, Sanders-Brown Center on Aging, University of Kentucky, Lexington, KY, USA. ' Department of Stroke and Cerebrovascular Diseases, National Cerebral and Cardiovascular Center, Osaka, Japan. ${ }^{10}$ Institute of Neuroscience, University of Newcastle-upon-Tyne, Newcastle-upon-Tyne, UK. ${ }^{11}$ Department of Clinical Genetics, Leiden University Medical Center, Leiden, Netherlands. ${ }^{12}$ Fraunhofer Institute for Cell Therapy and Immunology, Leipzig, Germany. ${ }^{13}$ Clinic for Nuclear Medicine, University of Leipzig, Leipzig, Germany. ${ }^{14}$ Institute for Anatomy, Faculty of Veterinary Medicine, University of Leipzig, Leipzig, Germany. ${ }^{15}$ Department of Neurology, Health Sciences Center, University of New Mexico, Albuquerque, NM, USA. ${ }^{16}$ Department of Pharmacology, Croatian Institute for Brain Research, University of Zagreb School of Medicine, Zagreb, Croatia. ${ }^{17}$ Institute of Biochemistry Food and Nutrition Science, Hebrew University of Jerusalem, Rehovot, Israel. ${ }^{18}$ Department of Human Genetics, Leiden University Medical Center, Leiden, Netherlands.

Received: 30 May 2016 Accepted: 12 January 2017

Published online: 25 January 2017

\section{References}

1. O'Brien JT, Thomas A. Vascular dementia. Lancet. 2015;386:1698-706.

2. Moorhouse P, Rockwood K. Vascular cognitive impairment: current concepts and clinical developments. Lancet Neurol. 2008;7:246-55.

3. Hachinski V, ladecola C, Petersen RC, Breteler MM, Nyenhuis DL, Black SE, Powers WJ, DeCarli C, Merino JG, Kalaria RN, Vinters HV, Holtzman DM, Rosenberg GA, Dichgans M, Marler JR, Leblanc GG. National Institute of Neurological Disorders and Stroke-Canadian Stroke Network vascular cognitive impairment harmonization standards. Stroke. 2006;37:2220-41.

4. Prins ND, Scheltens $P$. White matter hyperintensities, cognitive impairment and dementia: an update. Nat Rev Neurol. 2015;11:157-65.
5. Pantoni L. Cerebral small vessel disease: from pathogenesis and clinical characteristics to therapeutic challenges. Lancet Neurol. 2010;9:689-701.

6. Iadecola C. The pathobiology of vascular dementia. Neuron. 2013;80:844-66.

7. Toledo JB, Arnold SE, Raible K, Brettschneider J, Xie SX, Grossman M, Monsell SE, Kukull WA, Trojanowski JQ. Contribution of cerebrovascular disease in autopsy confirmed neurodegenerative disease cases in the National Alzheimer's Coordinating Centre. Brain. 2013;136:2697-706.

8. Thiel A, Cechetto DF, Heiss WD, Hachinski V, Whitehead SN. Amyloid burden, neuroinflammation, and links to cognitive decline after ischemic stroke. Stroke. 2014;45:2825-9.

9. Hainsworth AH, Markus HS. Do in vivo experimental models reflect human cerebral small vessel disease? A systematic review. J Cereb Blood Flow Metab. 2008;28:1877-91.

10. Jiwa NS, Garrard P, Hainsworth AH. Experimental models of vascular dementia and vascular cognitive impairment. A systematic review. J Neurochem. 2010;115:814-28.

11. Bailey EL, Smith C, Sudlow CL, Wardlaw JM. Is the spontaneously hypertensive stroke prone rat a pertinent model of sub cortical ischemic stroke? A systematic review. Int J Stroke. 2011;6:434-44.

12. Madigan JB, Wilcock DM, Hainsworth AH. Vascular contributions to cognitive impairment and dementia: topical review of animal models. Stroke. 2016:47:1953-9.

13. Woolf $\mathrm{SH}$. The meaning of translational research and why it matters. JAMA. 2008:299:211-3.

14. Hainsworth AH, Markus HS. Experimental animal models of cerebral small vessel disease. In: Pantoni L, Gorelick PB, editors. Cerebral Small Vessel Disease. Cambridge: Cambridge University Press; 2014. p. 42-51.

15. Landis SC, Amara SG, Asadullah K, Austin CP, Blumenstein R, Bradley EW, Crystal RG, Darnell RB, Ferrante RJ, Fillit $H$, Finkelstein R, Fisher M, Gendelman HE, Golub RM, Goudreau JL, Gross RA, Gubitz AK, Hesterlee SE, Howells DW, Huguenard J, Kelner K, Koroshetz W, Krainc D, Lazic SE, Levine MS, Macleod MR, McCall JM, Moxley III RT, Narasimhan K, Noble LJ, Perrin S, Porter JD, Steward O, Unger E, Utz U, Silberberg SD. A call for transparent reporting to optimize the predictive value of preclinical research. Nature. 2012:490:187-91.

16. Burrows FE, Bray N, Denes A, Allan SM, Schiessl I. Delayed reperfusion deficits after experimental stroke account for increased pathophysiology. J Cereb Blood Flow Metab. 2015;35:277-84.

17. Gibson CL, Coomber B, Murphy SP. Progesterone is neuroprotective following cerebral ischaemia in reproductively ageing female mice. Brain. 2011;134:2125-33.

18. McKittrick CM, Lawrence CE, Carswell HV. Mast cells promote blood brain barrier breakdown and neutrophil infiltration in a mouse model of focal cerebral ischemia. J Cereb Blood Flow Metab. 2015;35:638-47.

19. Baskerville TA, McCabe C, Weir CJ, Macrae IM, Holmes WM. Noninvasive MRI measurement of CBF: evaluating an arterial spin labelling sequence with 99mTc-HMPAO CBF autoradiography in a rat stroke model. J Cereb Blood Flow Metab. 2012;32:973-7.

20. Kitamura A, Fujita Y, Oishi N, Kalaria RN, Washida K, Maki T, Okamoto Y, Hase Y, Yamada M, Takahashi J, Ito H, Tomimoto H, Fukuyama H, Takahashi R, Ihara M. Selective white matter abnormalities in a novel rat model of vascular dementia. Neurobiol Aging. 2012;33:1012-35.

21. Holland PR, Searcy JL, Salvadores N, Scullion G, Chen G, Lawson G, Scott F, Bastin ME, Ihara M, Kalaria R, Wood ER, Smith C, Wardlaw JM, Horsburgh K. Gliovascular disruption and cognitive deficits in a mouse model with features of small vessel disease. J Cereb Blood Flow Metab. 2015;35:1005-14.

22. Okamoto Y, Yamamoto T, Kalaria RN, Senzaki H, Maki T, Hase Y, Kitamura A, Washida K, Yamada M, Ito H, Tomimoto H, Takahashi R, Ihara M. Cerebral hypoperfusion accelerates cerebral amyloid angiopathy and promotes cortical microinfarcts. Acta Neuropathol. 2012;123:381-94.

23. Kaiser D, Weise G, Moller K, Scheibe J, Posel C, Baasch S, Gawlitza M, Lobsien D, Diederich K, Minnerup J, Kranz A, Boltze J, Wagner DC. Spontaneous white matter damage, cognitive decline and neuroinflammation in middle-aged hypertensive rats: an animal model of early-stage cerebral small vessel disease. Acta Neuropathol Commun. 2014;2:169.

24. Brittain JF, McCabe C, Khatun H, Kaushal N, Bridges LR, Holmes WM, Barrick TR, Graham D, Dominiczak AF, Mhairi Macrae I, Hainsworth AH. An MRIhistological study of white matter in stroke-free SHRSP. I Cereb Blood Flow Metab. 2013;33:760-3.

25. Jalal FY, Yang Y, Thompson J, Lopez AC, Rosenberg GA. Myelin loss associated with neuroinflammation in hypertensive rats. Stroke. 2012;43:1115-22. 
26. Jalal FY, Yang Y, Thompson JF, Roitbak T, Rosenberg GA. Hypoxia-induced neuroinflammatory white-matter injury reduced by minocycline in SHR/SP. J Cereb Blood Flow Metab. 2015;35:1145-53.

27. Joutel A, Monet-Lepretre M, Gosele C, Baron-Menguy C, Hammes A, Schmidt S, Lemaire-Carrette B, Domenga V, Schedl A, Lacombe P, Hubner N. Cerebrovascular dysfunction and microcirculation rarefaction precede white matter lesions in a mouse genetic model of cerebral ischemic small vessel disease. J Clin Invest. 2010;120:433-45.

28. Joutel A, Faraci FM. Cerebral small vessel disease: insights and opportunities from mouse models of collagen IV-related small vessel disease and cerebral autosomal dominant arteriopathy with subcortical infarcts and leukoencephalopathy. Stroke. 2014;45:1215-21.

29. Dabertrand F, Kroigaard C, Bonev AD, Cognat E, Dalsgaard T, Domenga-Denier V, Hill-Eubanks DC, Brayden JE, Joutel A, Nelson MT. Potassium channelopathylike defect underlies early-stage cerebrovascular dysfunction in a genetic model of small vessel disease. Proc Natl Acad Sci U S A. 2015;112:E796-805.

30. Sudduth TL, Powell DK, Smith CD, Greenstein A, Wilcock DM. Induction of hyperhomocysteinemia models vascular dementia by induction of cerebral microhemorrhages and neuroinflammation. J Cereb Blood Flow Metab. 2013;33:708-15.

31. Troen AM, Shea-Budgell M, Shukitt-Hale B, Smith DE, Selhub J, Rosenberg IH. B-vitamin deficiency causes hyperhomocysteinemia and vascular cognitive impairment in mice. Proc Natl Acad Sci U S A. 2008;105:12474-9.

32. Boltze J, Forschler A, Nitzsche B, Waldmin D, Hoffmann A, Boltze CM, Dreyer AY, Goldammer A, Reischauer A, Hartig W, Geiger KD, Barthel H, Emmrich F, Gille U. Permanent middle cerebral artery occlusion in sheep: a novel large animal model of focal cerebral ischemia. J Cereb Blood Flow Metab. 2008;28:1951-64.

33. Boltze J, Nitzsche B, Geiger KD, Schoon HA. Histopathological investigation of different MCAO Modalities and impact of autologous bone marrow mononuclear cell administration in an ovine stroke model. Transl Stroke Res. 2011;2:279-93.

34. Wells AJ, Vink R, Blumbergs PC, Brophy BP, Helps SC, Knox SJ, Turner RJ. A surgical model of permanent and transient middle cerebral artery stroke in the sheep. PLoS One. 2012;7:e42157.

35. Dreyer A, Stroh A, Posel C, Findeisen M, von Geymuller T, Lobsien D, Nitzsche B, Boltze J. Frameless stereotaxy in sheep-neurosurgical and imaging techniques for translational stroke research. INTECH Open Access Publisher. 2012. doi:10.5772/32367.

36. Perez-Sanchez AP, Del-Angel-Caraza J, Quijano-Hernandez IA, BarbosaMireles MA. Obesity-hypertension and its relation to other diseases in dogs. Vet Res Commun. 2015;39:45-51.

37. Brown S, Atkins C, Bagley R, Carr A, Cowgill L, Davidson M, Egner B, Elliott J, Henik R, Labato M, Littman M, Polzin D, Ross L, Snyder P, Stepien R. Guidelines for the identification, evaluation, and management of systemic hypertension in dogs and cats. J Vet Intern Med. 2007;21:542-58.

38. Liu SK, Tilley LP, Tappe JP, Fox PR. Clinical and pathologic findings in dogs with atherosclerosis: 21 cases (1970-1983). J Am Vet Med Assoc. 1986;189:227-32.

39. Bernedo V, Insua D, Suarez ML, Santamarina G, Sarasa M, Pesini P. Betaamyloid cortical deposits are accompanied by the loss of serotonergic neurons in the dog. J Comp Neurol. 2009;513:417-29.

40. Uchida K, Nakayama H, Goto N. Pathological studies on cerebral amyloid angiopathy, senile plaques and amyloid deposition in visceral organs in aged dogs. J Vet Med Sci. 1991;53:1037-42.

41. Cotman CW, Head E. The canine (dog) model of human aging and disease: dietary, environmental and immunotherapy approaches. J Alzheimers Dis. 2008;15:685-707.

42. Schutt T, Helboe L, Pedersen LO, Waldemar G, Berendt M, Pedersen JT. Dogs with cognitive dysfunction as a spontaneous model for early Alzheimer's disease: a translational study of neuropathological and inflammatory markers. J Alzheimers Dis. 2016;52:433-49.

43. Head E, Moffat K, Das P, Sarsoza F, Poon WW, Landsberg G, Cotman CW, Murphy MP. Beta-amyloid deposition and tau phosphorylation in clinically characterized aged cats. Neurobiol Aging. 2005;26:749-63.

44. Nakamura S, Nakayama H, Kiatipattanasakul W, Uetsuka K, Uchida K, Goto N. Senile plaques in very aged cats. Acta Neuropathol. 1996;91:437-9

45. Vite $\mathrm{CH}$, Head E. Aging in the canine and feline brain. Vet Clin North Am Small Anim Pract. 2014;44:1113-29.

46. Littman MP. Spontaneous systemic hypertension in 24 cats. J Vet Intern Med. 1994;8:79-86.

47. Gieling E, Wehkamp W, Willigenburg R, Nordquist RE, Ganderup NC, van der Staay FJ. Performance of conventional pigs and Gottingen miniature pigs in a spatial holeboard task: effects of the putative muscarinic cognition impairer Biperiden. Behav Brain Funct. 2013;9:4.

48. Gieling ET, Schuurman T, Nordquist RE, van der Staay FJ. The pig as a model animal for studying cognition and neurobehavioral disorders. Curr Top Behav Neurosci. 2011;7:359-83.

49. Gieling ET, Nordquist RE, van der Staay FJ. Assessing learning and memory in pigs. Anim Cogn. 2011;14:151-73.

50. Grimberg-Henrici CG, Vermaak P, Elizabeth BJ, Nordquist RE, van der Staay FJ. Effects of environmental enrichment on cognitive performance of pigs in a spatial holeboard discrimination task. Anim Cogn. 2016;19(2):271-83.

51. Rioja-Lang FC, Roberts DJ, Healy SD, Lawrence AB, Haskell MJ. Dairy cow feeding space requirements assessed in a Y-maze choice test. J Dairy Sci. 2012:95:3954-60.

52. Moss MB, Jonak E. Cerebrovascular disease and dementia: a primate model of hypertension and cognition. Alzheimers Dement. 2007;3:S6-15.

53. Schmitt V, Pankau B, Fischer J. Old world monkeys compare to apes in the primate cognition test battery. PLoS One. 2012;7:e32024.

54. Csiszar A, Sosnowska D, Tucsek Z, Gautam T, Toth P, Losonczy G, Colman RJ, Weindruch R, Anderson RM, Sonntag WE, Ungvari Z. Circulating factors induced by caloric restriction in the nonhuman primate Macaca mulatta activate angiogenic processes in endothelial cells. J Gerontol A Biol Sci Med Sci. 2013;68:235-49.

55. Dal-Pan A, Pifferi F, Marchal J, Picq JL, Aujard F. Cognitive performances are selectively enhanced during chronic caloric restriction or resveratrol supplementation in a primate. PLoS One. 2011;6:e16581.

56. Mattison JA, Roth GS, Beasley TM, Tilmont EM, Handy AM, Herbert RL, Longo DL, Allison DB, Young JE, Bryant M, Barnard D, Ward WF, Qi W, Ingram DK, de Cabo R. Impact of caloric restriction on health and survival in rhesus monkeys from the NIA study. Nature. 2012;489:318-21.

57. Kuehnel F, Grohmann J, Buchwald U, Koeller G, Teupser D, Einspanier A. Parameters of haematology, clinical chemistry and lipid metabolism in the common marmoset and alterations under stress conditions. J Med Primatol. 2012;41:241-50

58. Mietsch M, Einspanier A. Non-invasive blood pressure measurement: values, problems and applicability in the common marmoset (Callithrix jacchus). Lab Anim. 2015:49:241-50.

59. Garosi LS, Dennis R, Penderis J, Lamb CR, Targett MP, Cappello R, Delauche AJ. Results of magnetic resonance imaging in dogs with vestibular disorders: 85 cases (1996-1999). J Am Vet Med Assoc. 2001;218:385-91.

60. Gray-Edwards HL, Salibi N, Josephson EM, Hudson JA, Cox NR, Randle AN, McCurdy VJ, Bradbury AM, Wilson DU, Beyers RJ, Denney TS, Martin DR. High resolution MRI anatomy of the cat brain at 3 Tesla. J Neurosci Methods. 2014:227:10-7.

61. Frey S, Pandya DN, Chakravarty MM, Bailey L, Petrides M, Collins DL. An MRI based average macaque monkey stereotaxic atlas and space (MNI monkey space). Neuroimage. 2011;55:1435-42.

62. Herrmann T, Mallow J, Plaumann M, Luchtmann M, Stadler J, Mylius J, Brosch M, Bernarding J. The travelling-wave primate system: a new solution for magnetic resonance imaging of macaque monkeys at 7 Tesla ultra-high field. PLoS One. 2015;10:e0129371.

63. McLaren DG, Kosmatka KJ, Oakes TR, Kroenke CD, Kohama SG, Matochik JA, Ingram DK, Johnson SC. A population-average MRI-based atlas collection of the rhesus macaque. Neuroimage. 2009:45:52-9.

64. Allen BS, Ko Y, Buckberg GD, Sakhai S, Tan Z. Studies of isolated global brain ischaemia: I. A new large animal model of global brain ischaemia and its baseline perfusion studies. Eur J Cardiothorac Surg. 2012;41:1138-46.

65. Bjarkam CR, Cancian G, Glud AN, Ettrup KS, Jorgensen RL, Sorensen JC. MRIguided stereotaxic targeting in pigs based on a stereotaxic localizer box fitted with an isocentric frame and use of SurgiPlan computer-planning software. J Neurosci Methods. 2009;183:119-26.

66. Schmidt MJ, Langen N, Klumpp S, Nasirimanesh F, Shirvanchi P, Ondreka N, Kramer M. A study of the comparative anatomy of the brain of domestic ruminants using magnetic resonance imaging. Vet J. 2012;191:85-93.

67. Nitzsche B, Frey S, Collins LD, Seeger J, Lobsien D, Dreyer A, Kirsten H, Stoffel MH, Fonov VS, Boltze J. A stereotaxic, population-averaged T1W ovine brain atlas including cerebral morphology and tissue volumes. Front Neuroanat. 2015;9:69.

68. Skinner JT, Moots PL, Ayers GD, Quarles CC. On the use of DSC-MRI for measuring vascular permeability. AJNR Am J Neuroradiol. 2016;37(1):80-7.

69. Chakravarty MM, Frey S, Collins DL. Digital atlas of the monkey brain in stereotactic co-ordinates. In: Paxinos G, Huang XF, Petrides M, Toga AW, 
editors. The Rhesus Monkey Brain In Stereotactic Coordinates. San Diego, CA: Academic; 2008.

70. Kohama SG, Rosene DL, Sherman LS. Age-related changes in human and non-human primate white matter: from myelination disturbances to cognitive decline. Age (Dordr). 2012;34:1093-110.

71. Conrad MS, Sutton BP, Dilger RN, Johnson RW. An in vivo three-dimensional magnetic resonance imaging-based averaged brain collection of the neonatal piglet (Sus scrofa). PLoS One. 2014;9:e107650.

72. Saikali S, Meurice P, Sauleau P, Eliat PA, Bellaud P, Randuineau G, Verin M, Malbert $\mathrm{CH}$. A three-dimensional digital segmented and deformable brain atlas of the domestic pig. J Neurosci Methods. 2010;192:102-9.

73. Datta R, Lee J, Duda J, Avants BB, Vite CH, Tseng B, Gee JC, Aguirre GD, Aguirre GK. A digital atlas of the dog brain. PLoS One. 2012;7:e52140.

74. Engel O, Kolodziej S, Dirnagl U, Prinz V. Modeling stroke in mice - middle cerebral artery occlusion with the filament model. J Vis Exp. 2011;(47):2423. doi: 10.3791/2423.

75. Macrae IM. Preclinical stroke research—advantages and disadvantages of the most common rodent models of focal ischaemia. Br J Pharmacol. 2011;164:1062-78.

76. Freret T, Schumann-Bard P, Boulouard M, Bouet V. On the importance of long-term functional assessment after stroke to improve translation from bench to bedside. Exp Transl Stroke Med. 2011;3:6.

77. Lalonde R. The neurobiological basis of spontaneous alternation. Neurosci Biobehav Rev. 2002;26:91-104.

78. Ryan CL, Doucette TA, Gill DA, Langdon KD, Liu Y, Perry MA, Tasker RA. An improved post-operative care protocol allows detection of long-term functional deficits following MCAo surgery in rats. J Neurosci Methods. 2006;154:30-7.

79. Carmo MR, Simoes AP, Fonteles AA, Souza CM, Cunha RA, Andrade GM. ATP P2Y1 receptors control cognitive deficits and neurotoxicity but not glial modifications induced by brain ischemia in mice. Eur J Neurosci. 2014;39:614-22.

80. Hattori K, Lee H, Hurn PD, Crain BJ, Traystman RJ, DeVries AC. Cognitive deficits after focal cerebral ischemia in mice. Stroke. 2000;31:1939-44.

81. Terpolilli NA, Kim SW, Thal SC, Kataoka H, Zeisig V, Nitzsche B, Klaesner B, Zhu C, Schwarzmaier S, Meissner L, Mamrak U, Engel DC, Drzezga A, Patel RP, Blomgren K, Barthel H, Boltze J, Kuebler WM, Plesnila N. Inhalation of nitric oxide prevents ischemic brain damage in experimental stroke by selective dilatation of collateral arterioles. Circ Res. 2012;110:727-38.

82. McGrath P. Observations on the intracranial carotid rete and the hypophysis in the mature female pig and sheep. J Anat. 1977;124:689-99.

83. Terlecki S, Baldwin BA, Bell FR. Experimental cerebral ischaemia in sheep. Neuropathology and clinical effects. Acta Neuropathol. 1967;7:185-200.

84. Zheng L, Vinters HV, Mack WJ, Zarow C, Ellis WG, Chui HC. Cerebral atherosclerosis is associated with cystic infarcts and microinfarcts but not Alzheimer pathologic changes. Stroke. 2013;44:2835-41.

85. Kalaria RN, Perry RH, O'Brien J, Jaros E. Atheromatous disease in small intracerebral vessels, microinfarcts and dementia. Neuropathol Appl Neurobiol. 2012;38:505-8.

86. Shibata M, Ohtani R, Ihara M, Tomimoto $\mathrm{H}$. White matter lesions and glial activation in a novel mouse model of chronic cerebral hypoperfusion. Stroke. 2004;35:2598-603.

87. Nishio K, Ihara M, Yamasaki N, Kalaria RN, Maki T, Fujita Y, Ito H, Oishi N, Fukuyama H, Miyakawa T, Takahashi R, Tomimoto H. A mouse model characterizing features of vascular dementia with hippocampal atrophy. Stroke. 2010;41:1278-84.

88. Hattori Y, Enmi J, Iguchi S, Saito S, Yamamoto Y, Tsuji M, Nagatsuka K, Kalaria RN, lida H, Ihara M. Gradual carotid artery stenosis in mice closely replicates hypoperfusive vascular dementia in humans. J Am Heart Assoc. 2016;5(2):e002757. doi:10.1161/JAHA.115.002757.

89. Hattori Y, Enmi J, Kitamura A, Yamamoto Y, Saito S, Takahashi Y, Iguchi S, Tsuji M, Yamahara K, Nagatsuka K, lida H, lhara M. A novel mouse model of subcortical infarcts with dementia. J Neurosci. 2015:35:3915-28.

90. Chen A, Akinyemi RO, Hase Y, Firbank MJ, Ndung'u MN, Foster V, Craggs LJ, Washida K, Okamoto Y, Thomas AJ, Polvikoski TM, Allan LM, Oakley AE, O'Brien JT, Horsburgh K, Ihara M, Kalaria RN. Frontal white matter hyperintensities, clasmatodendrosis and gliovascular abnormalities in ageing and post-stroke dementia. Brain. 2016;139:242-58.

91. Henning EC, Warach S, Spatz M. Hypertension-induced vascular remodeling contributes to reduced cerebral perfusion and the development of spontaneous stroke in aged SHRSP rats. J Cereb Blood Flow Metab. 2010;30:827-36.

92. Hainsworth $\mathrm{AH}$, Brittain JF, Khatun H. Pre-clinical models of human cerebral small vessel disease: utility for clinical application. J Neurol Sci. 2012;322:237-40.
93. Sironi L, Guerrini U, Tremoli E, Miller I, Gelosa P, Lascialfari A, Zucca I, Eberini I, Gemeiner M, Paoletti R, Gianazza E. Analysis of pathological events at the onset of brain damage in stroke-prone rats: a proteomics and magnetic resonance imaging approach. J Neurosci Res. 2004;78:115-22.

94. Weaver J, Jalal FY, Yang Y, Thompson J, Rosenberg GA, Liu KJ. Tissue oxygen is reduced in white matter of spontaneously hypertensive-stroke prone rats: a longitudinal study with electron paramagnetic resonance. J Cereb Blood Flow Metab. 2014;34:890-6.

95. Troen A, Rosenberg I. Homocysteine and cognitive function. Semin Vasc Med. 2005;5:209-14.

96. Troen AM. The central nervous system in animal models of hyperhomocysteinemia. Prog Neuropsychopharmacol Biol Psychiatry. 2005;29:1140-51.

97. Troen AM, Shukitt-Hale B, Chao WH, Albuquerque B, Smith DE, Selhub J, Rosenberg $J$. The cognitive impact of nutritional homocysteinemia in apolipoprotein-E deficient mice. J Alzheimers Dis. 2006;9:381-92.

98. Hainsworth AH, Yeo NE, Weekman EM, Wilcock DM. Homocysteine, hyperhomocysteinemia and vascular contributions to cognitive impairment and dementia (VCID). Biochim Biophys Acta. 2016;1862:1008-17.

99. Bernardo A, McCord M, Troen AM, Allison JD, McDonald MP. Impaired spatial memory in APP-overexpressing mice on a homocysteinemiainducing diet. Neurobiol Aging. 2007;28:1195-205.

100. Troen AM, Chao WH, Crivello NA, D'Anci KE, Shukitt-Hale B, Smith DE, Selhub J, Rosenberg $\mathrm{IH}$. Cognitive impairment in folate-deficient rats corresponds to depleted brain phosphatidylcholine and is prevented by dietary methionine without lowering plasma homocysteine. J Nutr. 2008;138:2502-9.

101. Fuso A, Nicolia V, Ricceri L, Cavallaro RA, Isopi E, Mangia F, Fiorenza MT, Scarpa S. S-adenosylmethionine reduces the progress of the Alzheimer-like features induced by B-vitamin deficiency in mice. Neurobiol Aging. 2012;33:1482-16.

102. Sudduth TL, Weekman EM, Brothers HM, Braun K, Wilcock DM. $\beta$-amyloid deposition is shifted to the vasculature and memory impairment is exacerbated when hyperhomocysteinemia is induced in APP/PS1 transgenic mice. Alzheimers Res Ther. 2014;6:32.

103. Ayata C, Dunn AK, Gursoy-Ozdemir Y, Huang Z, Boas DA, Moskowitz MA. Laser speckle flowmetry for the study of cerebrovascular physiology in normal and ischemic mouse cortex. J Cereb Blood Flow Metab. 2004;24:744-55.

104. Hallacoglu B, Sassaroli A, Fantini S, Troen AM. Cerebral perfusion and oxygenation are impaired by folate deficiency in rat: absolute measurements with noninvasive near-infrared spectroscopy. J Cereb Blood Flow Metab. 2011;31:1482-92.

105. Shaul ME, Hallacoglu B, Sassaroli A, Shukitt-Hale B, Fantini S, Rosenberg IH, Troen AM. Cerebral blood volume and vasodilation are independently diminished by aging and hypertension: a near infrared spectroscopy study. J Alzheimers Dis. 2014:42 Suppl 3:S189-98.

106. Tucsek Z, Toth P, Tarantini S, Sosnowska D, Gautam T, Warrington JP, Giles $\mathrm{CB}$, Wren JD, Koller A, Ballabh P, Sonntag WE, Ungvari Z, Csiszar A. Aging exacerbates obesity-induced cerebromicrovascular rarefaction, neurovascular uncoupling, and cognitive decline in mice. J Gerontol A Biol Sci Med Sci. 2014;69:1339-52.

107. Oomen CA, Farkas E, Roman V, van der Beek EM, Luiten PG, Meerlo P. Resveratrol preserves cerebrovascular density and cognitive function in aging mice. Front Aging Neurosci. 2009;1:4.

108. Brown WR, Blair RM, Moody DM, Thore CR, Ahmed S, Robbins ME, Wheeler KT. Capillary loss precedes the cognitive impairment induced by fractionated whole-brain irradiation: a potential rat model of vascular dementia. J Neurol Sci. 2007;257:67-71.

109. Hollander W, Prusty S, Kirkpatrick B, Paddock J, Nagraj S. Role of hypertension in ischemic heart disease and cerebral vascular disease in the cynomolgus monkey with coarctation of the aorta. Circ Res. 1977;40:170-83.

110. Kemper T, Moss MB, Hollander W, Prusty S. Microinfarction as a result of hypertension in a primate model of cerebrovascular disease. Acta Neuropathol. 1999:98:295-303.

111. Kemper TL, Blatt GJ, Killiany RJ, Moss MB. Neuropathology of progressive cognitive decline in chronically hypertensive rhesus monkeys. Acta Neuropathol. 2001;101:145-53.

112. Gaffan D. Recognition impaired and association intact in the memory of monkeys after transection of the fornix. J Comp Physiol Psychol. 1974;86: $1100-9$.

113. Mahut H, Zola-Morgan S, Moss M. Hippocampal resections impair associative learning and recognition memory in the monkey. J Neurosci. 1982;2:1214-20. 
114. Killiany R, Rehbein L, Mahut H. Developmental study of the hippocampal formation in rhesus monkeys (Macaca mulatta): II. Early ablations do not spare the capacity to retrieve conditional object-object associations. Behav Neurosci. 2005;119:651-61.

115. Rehbein L, Killiany R, Mahut H. Developmental study of the hippocampal formation in rhesus monkeys (Macaca mulatta): I. Early ablations spare discrimination learning but not recognition memory. Behav Neurosci. 2005;119:635-50.

116. Moore TL, Killiany RJ, Rosene DL, Prusty S, Hollander W, Moss MB. Impairment of executive function induced by hypertension in the rhesus monkey (Macaca mulatta). Behav Neurosci. 2002;116:387-96.

117. Schmidt F, Boltze J, Jager C, Hofmann S, Willems N, Seeger J, Hartig W, Stolzing A. Detection and quantification of beta-amyloid, pyroglutamyl abeta, and tau in aged canines. J Neuropathol Exp Neurol. 2015;74:912-23.

118. Head E, McCleary R, Hahn FF, Milgram NW, Cotman CW. Region-specific age at onset of beta-amyloid in dogs. Neurobiol Aging. 2000;21:89-96.

119. Cummings BJ, Su JH, Cotman CW, White R, Russell MJ. Beta-amyloid accumulation in aged canine brain: a model of early plaque formation in Alzheimer's disease. Neurobiol Aging. 1993;14:547-60.

120. Ishihara T, Gondo T, Takahashi M, Uchino F, Ikeda S, Allsop D, Imai K. Immunohistochemical and immunoelectron microscopical characterization of cerebrovascular and senile plaque amyloid in aged dogs' brains. Brain Res. 1991;548:196-205.

121. Uchida K, Miyauchi Y, Nakayama H, Goto N. Amyloid angiopathy with cerebral hemorrhage and senile plaque in aged dogs. Nihon Juigaku Zasshi. 1990;52:605-11.

122. Uchida K, Tani Y, Uetsuka K, Nakayama H, Goto N. Immunohistochemical studies on canine cerebral amyloid angiopathy and senile plaques. J Vet Med Sci. 1992;54:659-67.

123. Uchida K, Kuroki K, Yoshino T, Yamaguchi R, Tateyama S. Immunohistochemical study of constituents other than beta-protein in canine senile plaques and cerebral amyloid angiopathy. Acta Neuropathol. 1997;93:277-84.

124. Yoshino T, Uchida K, Tateyama S, Yamaguchi R, Nakayama H, Goto N. A retrospective study of canine senile plaques and cerebral amyloid angiopathy. Vet Pathol. 1996;33:230-4.

125. Walker LC. Animal models of cerebral beta-amyloid angiopathy. Brain Res Brain Res Rev. 1997;25:70-84.

126. Attems J, Jellinger KA, Lintner F. Alzheimer's disease pathology influences severity and topographical distribution of cerebral amyloid angiopathy. Acta Neuropathol. 2005;110:222-31.

127. Kang BT, Jang DP, Gu SH, Lee JH, Jung DI, Lim CY, Kim HJ, Kim YB, Kim HJ, Woo EJ, Cho ZH, Park HM. MRI features in a canine model of ischemic stroke: correlation between lesion volume and neurobehavioral status during the subacute stage. Comp Med. 2009;59:459-64.

128. Chambers JK, Uchida K, Nakayama H. White matter myelin loss in the brains of aged dogs. Exp Gerontol. 2012;47:263-9.

129. Su MY, Head E, Brooks WM, Wang Z, Muggenburg BA, Adam GE, Sutherland R, Cotman CW, Nalcioglu O. Magnetic resonance imaging of anatomic and vascular characteristics in a canine model of human aging. Neurobiol Aging. 1998;19:479-85.

130. Tapp PD, Siwak CT, Gao FQ, Chiou JY, Black SE, Head E, Muggenburg BA Cotman CW, Milgram NW, Su MY. Frontal lobe volume, function, and betaamyloid pathology in a canine model of aging. J Neurosci. 2004;24:8205-13.

131. Tapp PD, Head K, Head E, Milgram NW, Muggenburg BA, Su MY. Application of an automated voxel-based morphometry technique to assess regional gray and white matter brain atrophy in a canine model of aging. Neuroimage. 2006:29:234-44.

132. Chabriat H, Joutel A, Dichgans M, Tournier-Lasserve E, Bousser MG. Cadasil. Lancet Neurol. 2009:8:643-53.

133. Arboleda-Velasquez JF, Manent J, Lee JH, Tikka S, Ospina C, Vanderburg CR, Frosch MP, Rodriguez-Falcon M, Villen J, Gygi S, Lopera F, Kalimo $\mathrm{H}_{\text {, }}$ Moskowitz MA, Ayata C, Louvi A, Artavanis-Tsakonas S. Hypomorphic Notch 3 alleles link Notch signaling to ischemic cerebral small-vessel disease. Proc Natl Acad Sci U S A. 2011;108:E128-35.

134. Monet-Lepretre M, Bardot B, Lemaire B, Domenga V, Godin O, Dichgans M, Tournier-Lasserve E, Cohen-Tannoudji M, Chabriat H, Joutel A. Distinct phenotypic and functional features of CADASIL mutations in the Notch3 ligand binding domain. Brain. 2009;132:1601-12.

135. Ruchoux MM, Domenga V, Brulin P, Maciazek J, Limol S, Tournier-Lasserve E, Joutel A. Transgenic mice expressing mutant Notch3 develop vascular alterations characteristic of cerebral autosomal dominant arteriopathy with subcortical infarcts and leukoencephalopathy. Am J Pathol. 2003;162:329-42.

136. Rutten JW, Klever RR, Hegeman IM, Poole DS, Dauwerse HG, Broos LA, Breukel C, Aartsma-Rus AM, Verbeek JS, van der Weerd L, van Duinen SG, van den Maagdenberg AM, Lesnik Oberstein SA. The NOTCH3 score: a preclinical CADASIL biomarker in a novel human genomic NOTCH3 transgenic mouse model with early progressive vascular NOTCH3 accumulation. Acta Neuropathol Commun. 2015;3:89.

137. Wallays G, Nuyens D, Silasi-Mansat R, Souffreau J, Callaerts-Vegh Z, Van NA, Moons L, D'Hooge R, Lupu F, Carmeliet P, Collen D, Dewerchin M. Notch3 Arg170Cys knock-in mice display pathologic and clinical features of the neurovascular disorder cerebral autosomal dominant arteriopathy with subcortical infarcts and leukoencephalopathy. Arterioscler Thromb Vasc Biol. 2011;31:2881-8

138. Kilkenny C, Browne WJ, Cuthill IC, Emerson M, Altman DG. Improving bioscience research reporting: the ARRIVE guidelines for reporting animal research. PLoS Biol. 2010;8:e1000412.

139. Fisher M, Feuerstein G, Howells DW, Hurn PD, Kent TA, Savitz SI, Lo EH. Update of the stroke therapy academic industry roundtable preclinical recommendations. Stroke. 2009;40:2244-50.

140. Fisher M. Recommendations for advancing development of acute stroke therapies: Stroke Therapy Academic Industry Roundtable 3. Stroke. 2003;34: 1539-46.

\section{Submit your next manuscript to BioMed Central and we will help you at every step:}

- We accept pre-submission inquiries

- Our selector tool helps you to find the most relevant journal

- We provide round the clock customer support

- Convenient online submission

- Thorough peer review

- Inclusion in PubMed and all major indexing services

- Maximum visibility for your research

Submit your manuscript at www.biomedcentral.com/submit

) Biomed Central 